\title{
Primary Care Use of Laboratory Tests in Spain: Measurement Through Appropriateness Indicators
}

\author{
MARIA SALINAS ${ }^{1,2}$, MAITE LÓPEZ-GARRIGÓS ${ }^{1}$, CONSUELO TORMO ${ }^{3}$, JOAQUÍN URIS ${ }^{4}$ \\ ${ }^{I}$ Clinical Laboratory Department, University Hospital of San Juan, San Juan de Alicante, Spain \\ ${ }^{2}$ Biochemistry and Molecular Pathology Department, Miguel Hernandez University, Elche, Spain \\ ${ }^{3}$ Clinical Laboratory Department, Univsersity Hospital of Elche, Elche, Spain \\ ${ }^{4}$ Health Public Department, University of Alicante, Alicante, Spain
}

\begin{abstract}
SUMMARY
Background: To compare the inter-practice and inter-regional variability in laboratory test requests by general practitioners in Spain, through the measure of appropriateness indicators.

Methods: A call for data was posted on the Redconlab website. We obtained production statistics for 2010 from laboratories in 37 different hospitals from diverse Spanish regions. The following appropriateness indicators were calculated: test requests per 1000 inhabitants, ratios of related tests requests and index of variability. The results obtained in the laboratories in the region of authors were compared to the rest of the participating laboratories in order to establish whether there were regional differences in the test requesting patterns.

Results: The rate of request of the tests ranged from 31.5 per 1000 inhabitants for vitamin B12 to 372.6 per 1000 inhabitants for glucose. The index of variability ranged from 1.53 for glucose and triglycerides to 7.4 for alkaline phosphatase. Regarding the ratios of related test requests, the variability index ranged from 1.24 for folic acid/vitamin B12 to $\mathbf{2 6 . 3 8}$ for lactate dehydrogenase/alanine transaminase. The most frequently ordered tests were the ones with less variability, except for uric acid and urinalysis. No significant differences were identified between the results of the laboratories in the region of authors and the rest, except for urinalysis ( $p<0.001)$, folic acid/vita$\min \mathrm{B} 12(\mathrm{p}=\mathbf{0 . 0 3 0})$, and transferrin/ferritin $(\mathbf{p}=\mathbf{0 . 0 1 8})$.

Conclusions: A considerable variability exists in laboratory test ordering patterns by general practitioners across Spanish regions. Local habits must have been decisive as shown by the regional differences in the results of indicators of some tests. The study results bring out the need to accomplish interventions to improve appropriate use of laboratory tests.
\end{abstract}

(Clin. Lab. 2014;60:xx-xx. DOI: 10.7754/Clin.Lab.2013.130101)

\section{KEY WORDS}

benchmarking, clinical laboratory, indicators, variability

\section{INTRODUCTION}

The use of laboratory tests has increased over the last years [1], and Spain is not an exception [2]. Several studies have suggested that inappropriate test requests are a primary reason for such an increase [3]. The rate of inappropriate test requests ranges from $4.5 \%$ to $95 \%$, as shown by studies of medical records using implicit and explicit criteria [4]. Reasons for excessive tests ordered by physicians include defensive behavior and fear or uncertainty, lack of experience, the use of protocols and guidelines, "routine" clinical practice, inadequate educational feedback, and clinician's unawareness about the cost of examinations [5]. Inappropriate testing causes unnecessary patient discomfort, entails the risk of generating false/positive results, leads to overloading of the diagnostic services, wastes valuable healthcare resources, and is associated with other inefficiencies in healthcare delivery, undermining the quality of health services [6]. According to some authors [7], there is no clear correlation between the number of tests and the quality of patient care.

The "initial selection" of tests by clinicians could take

Manuscript accepted March 11, 2013 
Table 1. Laboratory organizational data.

\begin{tabular}{|c|c|c|c|}
\hline Patient served & \multicolumn{2}{|c|}{8130334 inhabitants } & $\%$ \\
\hline \multirow{2}{*}{ Geographical distribution } & \multicolumn{2}{|c|}{20 Valencian laboratories } & $54.0 \%$ \\
\hline & \multicolumn{2}{|c|}{17 Laboratories of other region } & $46.0 \%$ \\
\hline \multirow[b]{2}{*}{ Institution type } & Public & 34 & $92.0 \%$ \\
\hline & $\begin{array}{c}\text { Public with private } \\
\text { management }\end{array}$ & 3 & $8.0 \%$ \\
\hline \multirow{4}{*}{ Population served - number of primary health areas } & $40000-100000$ & 5 & $13.5 \%$ \\
\hline & $100000-200000$ & 11 & $29.7 \%$ \\
\hline & $200000-300000$ & 14 & $37.8 \%$ \\
\hline & $>300000$ & 7 & $18.9 \%$ \\
\hline \multirow{2}{*}{ Institution location } & \multicolumn{2}{|l|}{ Urban } & $78.0 \%$ \\
\hline & \multicolumn{2}{|c|}{ Rural } & $22.0 \%$ \\
\hline No. of beds, mean (CI 95\%) & \multicolumn{3}{|c|}{$431.45(321.02-541.88)$} \\
\hline
\end{tabular}

CI - Confidence interval of the mean.

into consideration the geological conditions, for example iodine deficiency in limestone regions that may lead to the increased frequency of specific tests. The topographical conditions may influence requests from rural or urban/industrial regions.

Inappropriate tests could be defined as "those that could reasonably be avoided at no significant detriment of patient care". Inappropriateness for over or under requesting could occur. The latter is more difficult to detect [8]. Identifying inadequacies in the use of diagnostic tests should be one of the duties of pathologists. For this purpose, the first step would be to examine the use of tests in our laboratory and compare it with others to examine overspending and to optimize the use of testing in order to reduce costs and increase the quality of the request process $[9,10]$.

The aim of our study was to compare the inter-practice and inter-regional variability in laboratory tests requested by general practitioners (GPs) in Spain, using the measurement of appropriateness indicators.

\section{MATERIALS AND METHODS}

\section{Data collection}

A call for data was posted on the Redconlab website. Spanish laboratories willing to participate in the study were invited to fill out an enrollment form and submit their results on-line. We obtained production statistics (number of tests requested by GPs) for 2010 from 37 laboratories at different hospitals from diverse regions across Spain. 28 clinical chemistry tests were examined in a cross-sectional study. These 28 parameters were selected based on previous experience in this field [11]. Every patient seen in any primary care center (PCC) of any of these 37 institutions, regardless of the reason for consultation, gender or age, was included in the study. Each participating laboratory was required to be able to obtain patient data from local databases and to provide organizational data (i.e., population served, public/private management, number of beds, location).

\section{Data processing}

After collecting data, 2 types of appropriateness indicators were calculated by a single coordination center: test requests per 1000 inhabitants or ratios of related tests requests. In order to explore the inter-practice variability, a third indicator, the "index of variability", was calculated as follows: top decile divided by bottom decile. With these data, a frequency histogram and a box plot for each of the indicators was drawn, and a pre-pre-analytical quality control report was prepared. This report was sent to each participating laboratory indicating their individual results compared to those of the others. Each report had 28 sheets, each including a single indicator: test ordered per 1000 inhabitants for 16 tests and ratios for 12 related test requests (Figure 1).

The indicators obtained in the laboratories in the region of authors (the Valencian Community, 20 laboratories; 4150793 patients) were compared to the pooled results of the remaining ones (17 laboratories; 3979541 patients) in order to establish whether there were regional differences in the requesting patterns. In addition, the indicators were compared by location of hospitals (rural vs. urban).

\section{Statistical methods}

The statistical treatment of the previously calculated data included: the distribution, the mean, $95 \%$ confidence level for the mean, standard deviation, median, and in- 
Table 2. Mean, median, range and variability index (Percentil90/Percentil10) of every indicator result.

\begin{tabular}{|c|c|c|c|c|}
\hline & Mean & Median & Range & Variability index* \\
\hline \multicolumn{5}{|c|}{ Tests requesting per 1000 inhabitants } \\
\hline Glucose & 372.6 & 366.4 & $227.9-486.3$ & 1.5 \\
\hline Triglycerides & 342.4 & 333.2 & 226.7 - 456.2 & 1.5 \\
\hline Cholesterol & 357.1 & 353.3 & $226.3-470.9$ & 1.5 \\
\hline Creatinine & 351.7 & 344.5 & 184.1 - 481.9 & 1.6 \\
\hline Alanine transaminase (ALT) & 332 & 329 & $179.0-490.1$ & 1.7 \\
\hline Cholesterol. HDL & 275 & 279 & $131.5-407.0$ & 1.8 \\
\hline Glycosylated hemoglobin & 85 & 88.8 & $53.0-134.5$ & 2.0 \\
\hline Thyrotropin (TSH) & 174.4 & 178.6 & $108.1-285.4$ & 2.1 \\
\hline Prostate-specific antigen (PSA) & 51.1 & 51 & $19.1-85.2$ & 2.1 \\
\hline Uric acid & 298.5 & 302.1 & 106.4 - 434.0 & 2.2 \\
\hline Ferritin & 130.9 & 127 & $74.7-202.7$ & 2.2 \\
\hline C-Reactive protein (CRP) & 60.6 & 53.1 & $21.2-239.8$ & 3.5 \\
\hline Urinalysis & 196.7 & 211.2 & 18.2 - 345.2 & 3.8 \\
\hline Vitamin B 12 & 31.5 & 27.8 & $4.0-88.0$ & 6.4 \\
\hline Calcium (Ca) & 88.2 & 80.3 & $14.9-291.4$ & 7.0 \\
\hline Alkaline phosphatase (ALP) & 139.1 & 125.5 & 9.3 - 306.5 & 7.4 \\
\hline \multicolumn{5}{|c|}{ Related test requesting ratio } \\
\hline Folic acid/Vitamin B 12 & 0.9 & 1.0 & $0.5-1.2$ & 1.2 \\
\hline Gamma-Glutamyltransferase (GGT)/ALT & 0.8 & 0.9 & $0.2-1.0$ & 2.1 \\
\hline Iron/Ferritin & 1.0 & 1.0 & $0.3-1.9$ & 2.4 \\
\hline Aspartate transaminase (AST)/ALT & 0.8 & 0.9 & 0.1 - 1.0 & 2.8 \\
\hline Phosphate/Ca & 0.7 & 0.7 & $0.1-1.0$ & 3.3 \\
\hline Total bilirubin (tBILT)/ALP & 1.2 & 1.0 & $0.3-6.4$ & 4.3 \\
\hline Urea/Creatinine & 0.6 & 0.6 & 0.0 - 1.1 & 5.6 \\
\hline Thyroxine (FT4)/TSH & 0.4 & 0.3 & $0.1-1.0$ & 6.1 \\
\hline Free PSA (FPSA)/PSA & 0.1 & 0.1 & $0.0-0.5$ & 9.4 \\
\hline Transferrin/Ferritin & 0.4 & 0.3 & 0.0 - 1.0 & 12.3 \\
\hline Direct bilirubin/tBIL & 0.1 & 0.1 & $0.0-0.9$ & 23.2 \\
\hline Lactate dehydrogenase (LDH)/ALT & 0.1 & 0.1 & $0.0-0.7$ & 26.4 \\
\hline
\end{tabular}

* - P90/P10.

terquartile range.

The analysis of the distribution was conducted by way of the Kolmogorov-Smirnov test. A $t$-test analysis was conducted to examine if there were regional differences or laboratory locations in the results of the indicators that followed a normal distribution, and a Kruskal-Wallis test analysis to show whether the indicators followed a non-Gaussian distribution. A two-sided $\mathrm{p} \leq 0.05$ rule was utilized as the criterion for rejecting the null hypothesis of no difference.

\section{RESULTS}

Table 1 displays a summary of the organizational data of the different laboratories that participated in the study. In all laboratories tests could be either requested in profiles or individually.

As shown in Table 2, the rate of request of the tests ranged from 31.5 per 1000 inhabitants for vitamin B12 to 372.6 per 1000 inhabitants for glucose. The index of variability ranged from 1.5 for glucose and triglycerides to 7.4 for alkaline phosphatase (ALP). Regarding the ra- 
Table 3. Comparison between Spanish regions: Valencia Community, other Spanish regions and p-value of every indicator result.

\begin{tabular}{|c|c|c|c|}
\hline & Valencia Community & Other Spanish Regions & \\
\hline \multicolumn{4}{|c|}{ Tests requesting per 1000 inhabitants } \\
\hline & Mean \pm SD & Mean \pm SD & $\mathbf{p}$ \\
\hline Alanine transaminase (ALT) & $329.4 \pm 70.2$ & $335.2 \pm 62.6$ & 0.794 \\
\hline Cholesterol & $348.2 \pm 57.1$ & $367.6 \pm 57.6$ & 0.311 \\
\hline Cholesterol, HDL & $263.6 \pm 58.0$ & $288.4 \pm 68.1$ & 0.238 \\
\hline Creatinine & $346.6 \pm 65.9$ & $357.7 \pm 64.0$ & 0.607 \\
\hline Ferritin & $127.1 \pm 33.4$ & $135.4 \pm 34.6$ & 0.480 \\
\hline Glucose & $369.5 \pm 59.2$ & $376.2 \pm 66.0$ & 0.748 \\
\hline Glycosylated hemoglobin & $87.7 \pm 18.8$ & $81.9 \pm 26.5$ & 0.439 \\
\hline Prostate-specific antigen (PSA) & $50.6 \pm 12.2$ & $51.6 \pm 16.6$ & 0.829 \\
\hline Thyrotropin (TSH) & $166.5 \pm 39.5$ & $183.6 \pm 43.5$ & 0.218 \\
\hline Triglycerides & $338.3 \pm 54.2$ & $347.1 \pm 54.0$ & 0.622 \\
\hline Uric acid & $291.8 \pm 71.0$ & $306.2 \pm 79.0$ & 0.562 \\
\hline \multirow[t]{2}{*}{ Urinalysis } & $159.1 \pm 74.1$ & $241.0 \pm 49.0$ & $<0.001 *$ \\
\hline & Median - (IQR) & Median - (IQR) & $\mathbf{p}$ \\
\hline Alkaline phosphatase (ALP) & $112.3-(64.1-179.9)$ & $162.7-(117.3-188.9)$ & 0.055 \\
\hline Calcium (Ca) & $62.7-(37.7-107.5)$ & 94.5 - (58.3 - 110.8) & 0.161 \\
\hline C-Reactive protein (CRP) & $57.6-(44.1-73.3)$ & $51.8-(29.5-63.3)$ & 0.247 \\
\hline Vitamin B 12 & $22.9-(16.2-35.9)$ & $32.1-(14.58-53.2)$ & 0.487 \\
\hline \multicolumn{4}{|c|}{ Related test requesting ratio } \\
\hline & Mean \pm SD & Mean \pm SD & $\mathbf{p}$ \\
\hline Aspartate transaminase (AST)/ALT & $0.75 \pm 0.29$ & $0.81 \pm 0.28$ & 0.494 \\
\hline Folic acid/Vitamin B12 & $0.97 \pm 0.09$ & $0.88 \pm 0.13$ & $0.030 *$ \\
\hline Gamma-Glutamyltransferase (GGT)/ALT & $0.74 \pm 0.23$ & $0.84 \pm 0.15$ & 0.131 \\
\hline Iron/Ferritin & $0.96 \pm 0.27$ & $1.10 \pm 0.40$ & 0.251 \\
\hline \multirow[t]{2}{*}{ Phosphate/Ca } & $0.66 \pm 0.20$ & $0.65 \pm 0.27$ & 0.862 \\
\hline & Median - (IQR) & Median - (IQR) & $\mathbf{p}$ \\
\hline Direct bilirubin/BILT & $0.06-(0.03-0.15)$ & $0.05-(0.03-0.07)$ & 0.211 \\
\hline Free PSA (FPSA)/PSA & $0.15-(0.10-0.20)$ & $0.12-(0.10-0.14)$ & 0.120 \\
\hline Lactate dehydrogenase (LDH)/ALT & $0.05-(0.02-0.16)$ & $0.11-(0.04-0.31)$ & 0.120 \\
\hline Thyroxine (FT4)/TSH & $0.31-(0.24-0.45)$ & $0.31-(0.21-0.49)$ & 0.903 \\
\hline Total bilirubin (BILT)/ALP & $0.99-(0.75-1.27)$ & $1.05-(0.97-1.21)$ & $\mathbf{0 . 3 3 4}$ \\
\hline Transferrin/Ferritin & $0.24-(0.17-0.51)$ & $0.51-(0.25-0.87)$ & $0.022 *$ \\
\hline Urea/Creatinine & $0.58-(0.29-0.91)$ & $0.73-(0.44-0.96)$ & 0.315 \\
\hline
\end{tabular}

$*$ - $\mathbf{p}<0.05$.

tios of related test requests, the variability between laboratories was even greater. The variability index for these indicators ranged from 1.2 for folic acid/vitamin B12 to 26.4 for lactate dehydrogenase ( $\mathrm{LDH}) /$ alanine transaminase (ALT).

The most frequently requested tests were the ones with less variability, except for uric acid and urinalysis. Table 2 shows the descriptive analysis of the different indicators of laboratory tests requested according to their variability index.

Table 3 compares the appropriateness indicators obtained at the laboratories in the region of authors (the $\mathrm{Va}$ - 
Table 4. Comparison between hospital location: Rural, urban and p-value of every indicator result.

\begin{tabular}{|c|c|c|c|}
\hline & Rural & Urban & \\
\hline \multicolumn{4}{|c|}{ Tests requesting per 1000 inhabitants } \\
\hline & Mean \pm SD & Mean \pm SD & $\mathbf{p}$ \\
\hline Alanine transaminase (ALT) & $342.0 \pm 84.5$ & $329.3 \pm 61.4$ & 0.635 \\
\hline Cholesterol & $359.2 \pm 68.4$ & $356.5 \pm 55.4$ & 0.907 \\
\hline Cholesterol, HDL & $267.4 \pm 68.1$ & $277.1 \pm 62.9$ & 0.706 \\
\hline Creatinine & $362.6 \pm 74.2$ & $348.7 \pm 62.5$ & 0.598 \\
\hline Ferritin & $124.0 \pm 44.2$ & $133.0 \pm 30.7$ & 0.517 \\
\hline Glucose & $382.6 \pm 67.9$ & $369.9 \pm 60.8$ & 0.613 \\
\hline Glycosylated hemoglobin & $92.3 \pm 29.5$ & $83.0 \pm 20.4$ & 0.307 \\
\hline Prostate-specific antigen (PSA) & $59.6 \pm 16.7$ & $48.7 \pm 12.8$ & 0.054 \\
\hline Thyrotropin (TSH) & $184.9 \pm 63.4$ & $171.5 \pm 34.5$ & 0.426 \\
\hline Triglycerides & $344.5 \pm 66.0$ & $341.8 \pm 51.0$ & 0.901 \\
\hline Uric acid & $331.5 \pm 68.8$ & $289.3 \pm 74.0$ & 0.157 \\
\hline \multirow[t]{2}{*}{ Urinalysis } & $196.7 \pm 87.6$ & $196.7 \pm 73.4$ & 0.999 \\
\hline & Median - (IQR) & Median - (IQR) & $\mathbf{p}$ \\
\hline Alkaline phosphatase (ALP) & $69.1-(37.7-131.4)$ & $141.8(102.6$ - 188.5) & 0.658 \\
\hline Calcium $(\mathbf{C a})$ & $94.7-(26.5-176.9)$ & 80.4 - (48.6 - 108.5) & 0.150 \\
\hline C-Reactive protein (CRP) & 53.0 - (36.0 - 78.0) & $53.1-(37.3-67.3)$ & 0.971 \\
\hline Vitamin B 12 & $19.6-(16.5-37.5)$ & $29.3-(16.2-13.5)$ & 0.666 \\
\hline \multicolumn{4}{|c|}{ Related test requesting ratio } \\
\hline & Mean \pm SD & Mean \pm SD & $\mathbf{p}$ \\
\hline Aspartate transaminase (AST)/ALT & $0.87 \pm 0.26$ & $0.76 \pm 0.28$ & 0.325 \\
\hline Folic acid/Vitamin B12 & $0.99 \pm 0.10$ & $0.91 \pm 0.12$ & 0.108 \\
\hline Gamma-Glutamyltransferase (GGT)/ALT & $0.79 \pm 0.19$ & $0.78 \pm 0.21$ & 0.955 \\
\hline Iron/Ferritin & $0.87 \pm 0.28$ & $1.07 \pm 0.34$ & 0.154 \\
\hline \multirow[t]{2}{*}{ Phosphate/Ca } & $0.50 \pm 0.19$ & $0.70 \pm 0.22$ & $0.024 *$ \\
\hline & Median - (IQR) & Median - (IQR) & $\mathbf{p}$ \\
\hline Direct bilirubin/BILT & $0.03-(0.03-0.15)$ & $0.05-(0.03-0.08)$ & $\mathbf{0 . 7 9 5}$ \\
\hline Free PSA (FPSA)/PSA & $0.11-(0.08-0.26)$ & $0.14-(0.11-0.18)$ & 0.796 \\
\hline Lactate dehydrogenase (LDH)/ALT & $0.09-(0.03-0.19)$ & $0.06-(0.03-0.22)$ & 0.971 \\
\hline Thyroxine (FT4)/TSH & $0.21-(0.13-0.30)$ & $0.34-(0.24-0.49)$ & $0.012 *$ \\
\hline Total bilirubin (BILT)/ALP & $1.17-(1.05-1.36)$ & $1.00-(0.88-1.16)$ & 0.105 \\
\hline Transferrin/Ferritin & $0.31-(0.16-0.63)$ & $0.34-(0.2-0.7)$ & 0.556 \\
\hline Urea/Creatinine & $0.67-(0.57-0.93)$ & $0.64-(0.31-0.94)$ & 0.507 \\
\hline
\end{tabular}

$*-\mathbf{p}<\mathbf{0 . 0 5}$.

lencian Community) and the ones obtained for the rest, in alphabetical order.

No significant differences were noticed between our results and those of other Spanish regions, except for urinalysis $(p<0.001)$, folic acid/vitamin B12 ( $=0.030)$ and transferrin/ferritin $(\mathrm{p}=0.018)$ ratios.

Table 4 compares appropriateness indicators obtained in the rural location and those of the urban laboratories. No significant differences were obtained between test ordering patterns by general practitioners in rural or urban locations, except for phosphate $(\mathrm{P}) /$ calcium $(\mathrm{Ca})$ and free thyroxine (FT4)/thyrotropin (TSH). 


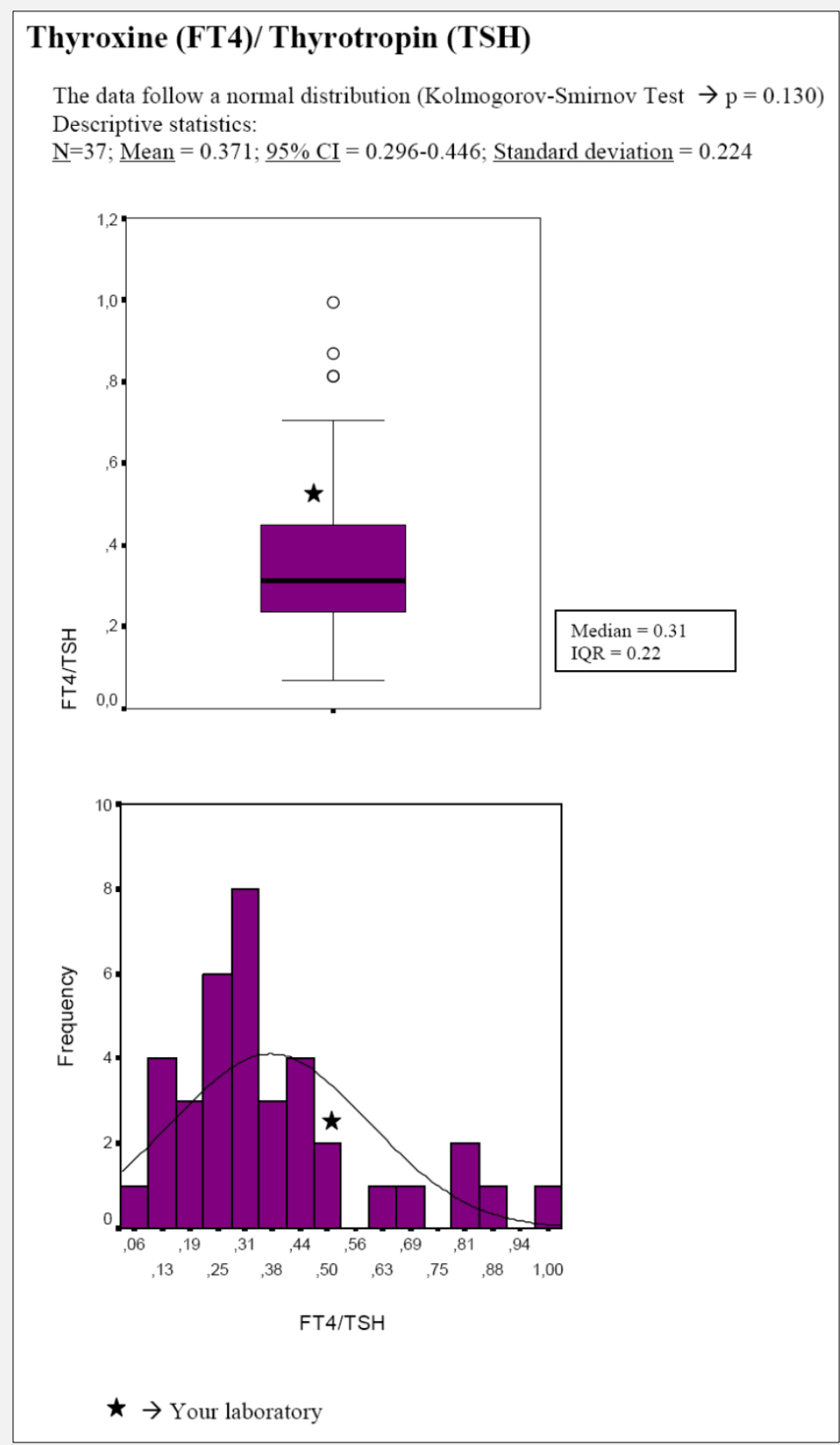

Figure 1. One of the report sheets sent to every laboratory that participated in the study.

\section{DISCUSSION}

This is the first study that evaluates the use of laboratory tests in primary care in different health care regions in Spain. It shows a high variability in every indicator studied. In general, the less the test is requested the more variability is observed.
The observed variability is very difficult to explain based only on differences in the characteristics of the patients. Local habits must have been decisive as shown by the regional differences in the results of indicators of some tests. There was not a systematic over or under requesting in any region compared to the others. In the inter-regional comparison, urinalysis was considerably 
over-requested when compared with the Valencian Community; however, folate and transferrin were under-requested.

Current guidelines recommend an active request of triglycerides, glucose, creatinine, glycosylated hemoglobin, ferritin, thyrotropin (TSH), and calcium [11] to depict treatable diseases in an early stage. The previous guidelines, however, do not state which reference values should be achieved. Accordingly, the question is: to what levels should we stimulate demand for those tests? Triglycerides, cholesterol, creatinine, and glucose are considered routine laboratory tests for preventive health exams to promote healthier behaviours, and their high demand may be justified. On the other hand, glycosylated hemoglobin [12] and TSH are probably under requested [13]. The first is the best disease marker in diabetic patients and its use has been extended not only to monitor but also to the diagnosis of the disease [14]. The latter is very useful to detect thyroid dysfunction, especially in middle aged women and older patients that may have very unclear symptoms [13].

Regarding ferritin, should it be requested in primary care only when microcytic anemia is diagnosed? Should it also be requested in subjects without anemia to investigate iron deposits? Its demand in some areas (200/ 1000 inhabitants) seems to be too high if we consider it appropriate to request it only in patients with anemia [15]. Indeed, there are different points of view in literature with respect to which marker should be chosen in patients with microcytic anemia. Some authors recommend ferritin as the front line marker [16], while others propose transferrin and transferrin saturation index. Ferritin results might be biased in some cases as elevated levels are seen in inflammations, malignant diseases, and alcoholism. By analysing ferritin and transferrin together, the majority of iron-metabolism disorders can be explained (in conjunction with a blood smear). However, ferritin is still considered the first marker for early depiction of uncomplicated iron deficiency, such as preventive health exams or during pregnancy.

There was a high variability in the request of calcium, ranging from 14.9 to 291.4 per 1000 inhabitants. It suggests that calcium could be under requested in some areas, which could indicate that hyperparathyroidism may be overlooked. The group of middle-aged women is not the only group for a thyroid disorder. They often suffer from hyperparathyroidism, which is detected either too late or by chance. Hyperparathyroidism has very diffuse symptoms and elevated serum calcium levels can unmask the disease. The results of this study show that the use of calcium should be encouraged in less demanding areas.

The results of the indicators suggest that uric acid may be over requested [7]. This could be potentially dangerous since its use for screening purposes may lead to treatment of "asymptomatic hyperuricemia" or overload the rheumatology consultation. Unexpected pathologic values could cause unneeded repeated visits.

Although urinalysis is not recommended as a screening test for reasons of cost-benefit, the study results show that it continues to be frequently requested in primary care services. This high request for urinalysis may be due to the noninvasive type of test that provides an overview of the situation of the patients.

It is difficult to justify a request of prostate-specific antigen (PSA) in primary care patients since nowadays its usefulness for screening purposes is controversial, even when requested in those older than 50 [17].

The behavior of the request of some tests has been measured through indicators of ratios of related test requests. It is a practical way not only to measure requesting activity but especially to monitor changes over time. Values below 1 are recommended. In our study this occurred for free-thyroxine/TSH, direct bilirubin/total bilirubin (tBIL), and free-PSA/total-PSA. There was, however, a great variability between areas.

Serum ALT is the recommended screening test for liver disease, ALP is the second choice and bilirubin should be requested only when icterus is suspected [18].

Such an approach would reduce aspartate transaminase (AST)/ALT, tBIL/ALP, LDH/ALT and gamma-glutamyl transferase (GGT)/ALT ratios. In the PCC of certain health care areas the liver test profile - that can be requested by simply checking a box - includes more than one of those tests. This probably resulted in laboratory misuse. It is well known that even if the single tests are relatively cheap the results may cause an expensive state of "a person with an abnormal laboratory value" [19]. We found a wide variability in the urea/creatinine index, indicating that urea could be requested in excess. Urea is not an organ-specific test and creatinine is a better marker of renal function.

To summarize, the results of the indicators for uric acid, urianalysis, AST, and urea are possibly overused and glycosylated hemoglobin, TSH, and calcium seems underused in most Spanish regions.

The main limitation of the study is that the differences in test requesting patterns could be explained by case mix variations in the different PCCs, the possible variability in the patient population they attended or the use of different request forms or panels by the doctors.

\section{CONCLUSION}

The study results emphasize the need to accomplish interventions to improve appropriate laboratory use. Interdepartmental and inter-regional cooperation would be crucial to develop protocols and guidelines in order to optimize the use of laboratory tests, which support many clinical decisions [20].

\section{Acknowledgement:}

Members of the REDCONLAB working group are the following: Arturo Carratala (Hospital Clínico Universitario de Valencia); Juan Ignacio Molinos (Hospital Comarcal de Sierrallana (Torrelavega)); Ana Santo- 
Quiles (Hospital Virgen de la Salud (Elda)); Julian Díaz (Hospital Francesc de Borja (Gandía)); Silvia Pesudo (Hospital de La Plana (Castellon)); Luis Rabadán (Complejo Hospitalario de Soria); Raquel Blázquez (Hospital Universitario de Móstoles); M. Amalia Andrade-Olivié ( Hospital Xeral - Complejo Hospitalario Universitario de Vigo); José Sastre (Hospital Virgen de los Lirios (Alcoy)); Jose V Garcia Lario (Hospital Universitario Virgen de las Nieves); Laura Navarro (Consorcio Hospitalario de Albacete); Mario Ortuño (Hospital Universitario de la Ribera); Maria Angeles Giménez (Hospital de Antequera); Jose Antonio Ferrero (Hospital General de Castellón); Maria del Pilar Megia (Hospital Virgen de Altagracia (Ciudad Real)); Juan Bautista Ortola (Hospital de Denia); Berta Gonzalez-Ponce (Hospital Da Costa (Burela)); Vicente Granizo (Hospital Universitario de Guadalajara); Isidoro Herrera (Complejo Hospitalario de Jaen); Martin Yago (Hospital General de Requena); Diego Benitez (Hospital Vega Baja); Virtudes Chinchilla (Hospital General Universitario de Alicante); Pilar Garcia-Chico (Hospital General Universitario de Ciudad Real); Mercé Ribelles (Hospital Arnau de Vilanova (Lleida)); Jose Luis Barberá (Hospital de Manises); Felix Gascon (Hospital Valle de los Pedroches (Pozoblanco)); Amparo Miralles (Hospital de Sagunto); Rafael Sánchez-Parrilla (Hospital Universitario Joan XXIII (Tarragona)); Juan Molina (Hospital Comarcal de la Marina Baixa); Goitzane Marcaida (Consorcio Hospital General Universitario de Valencia); Begoña Laíz (Hospital Universitario La Fe); Carmen Vinuesa (Hospital de Vinaros); Maria Fatas (Hospital Universitario Severo Ochoa); Francisco Miralles (Hospital Lluis Alcanyis (Xativa)) and Maria Victoria Poncela-Garcia (Complejo Asistencial Universitario de Burgos).

\section{Declaration of Interest:}

None

\section{References:}

1. Fowkes FG. Containing the use of laboratory tests. BMJ 1985; 290:488.

2. Pons AR, Garcia-Raja A, Antich B, et al. Multidisciplinary model in the efficient clinical management of requested tests. Rev Lab Clin 2010;3:171-6.

3. Bareford D, Hayling A. Innappropriate use of laboratory services: long term combined approach to modify request patterns. BMJ 1990;301:1305-7.

4. Van Walraven C, Naylor CD. Do we know what inappropriate laboratory utilization is? A systematic review of laboratory clinical audits. JAMA 1998;280:550-8.
5. Rodriguez-Espinosa J. Clinical laboratory: use and misuse, management models and health expenditure. Med Clin (Barc) 2005; $125: 622-5$.

6. Laposata M, Dighe A. "Pre-pre" and "post-post" analytical error: high-incidence patient safety hazards involving the clinical laboratory. Clin Chem Lab Med 2007;45:712-9.

7. Larsson A. Can we learn from studies on regional differences in the utilization of laboratory tests? Ups J Med Sci 2011;116:225-6.

8. Smellie WSA. Appropiateness of test use in pathology: a new era or reinventing the wheel? Ann Clin Biochem 2003;40:585-92.

9. Smellie WSA, Galloway MJ, Chinn D. Benchmarking general practice use of pathology services: a model for monitoring change. J Clin Pathol 2000;53:476-80.

10. Calderon-Margalit R, Mor-Yosef S, Mayer M, Adler B, Shapira SC. An administrative intervention to improve the utilization of laboratory tests within a university hospital. Int $\mathbf{J}$ Qual Health Care 2005; $17: 243-8$

11. Larsson A, Palmer M, Hultén G, Tryding N. Large differences in laboratory utilisation between hospitals in Sweden. Clin Chem Lab Med 2000;38:383-9.

12. Salinas M, López-Garrigós M, Pomares F, et al. An Evaluation of Hemoglobin A1c Test Ordering Patterns in a Primary Care Setting. Lab Medicine 2012;43:44-6.

13. Parle JV, Franklyn JA, Cross KW, Jones SC, Sheppard MC Prevalence and follow-up of abnormal thyrotrophin (TSH) concentrations in the elderly in the United Kingdom. ClinEndocrin 1991;34:77-83.

14. Standards of Medical Care in Diabetes - 2010. American Diabetes Association. Diabetes Care 2011;3:511-61.

15. Smellie WS, Forth J, Bareford D, et al. Best practice in primary care pathology: review 3. J Clin Pathol 2006;59:781-9.

16. Galloway MJ, Smellie WS. Investigating iron status in microcytic anaemia. BMJ 2006;333:791-3.

17. Lumbreras B, Salinas M, López-Garrigós M. Variation in PSA tests ordering in primary care centers: tendencies 2002-2009. Clin Lab 2012;58:573-7.

18. Salinas M, López-Garrigós M, Lugo J, Gutiérrez M, Flors L, Leiva-Salinas C. Diagnostic accuracy of icteric index to detect abnormal total bilirubin values. J Clin Pathol 2012;65:928-33.

19. Tryding N, Hultdin J, Larsson A. Continuing education is the correct way to influence the use of laboratory analyses. Lakartidningen 2004;101:495-6.

20. Forsman RW. Why is the laboratory an afterthought for managed care organizations? Clin Chem 1996;42:813-6.

Correspondence:

Maria Salinas PhD

University Hospital of San Juan

Carretera Alicante-Valencia

s/n. 03550 San Juan de Alicante, Spain

Tel.: + 34-965938877

Fax: + 34-965938683

Email: salinas_mar@gva.es 